\title{
Corneal clarity measurements in patients with keratoconus undergoing either penetrating or deep anterior lamellar keratoplasty
}

This article was published in the following Dove Press journal:

Clinical Ophthalmology

\author{
Khaled Alzahrani ${ }^{1,2}$ \\ Syarifah-Faiza Dardin' \\ Fiona Carley ${ }^{2}$ \\ Arun Brahma ${ }^{2}$ \\ Debbie Morley² \\ M Chantal Hillarby' \\ 'Division of Pharmacy and Optometry, \\ School of Health Sciences, University \\ of Manchester, Manchester, UK; \\ ${ }^{2}$ Manchester Royal Eye Hospital, \\ Central Manchester University \\ Hospitals NHS Foundation Trust, \\ Manchester Academic Health Science \\ Centre, Manchester, UK
}

Correspondence: Khaled Alzahrani Research department, 4th floor, Manchester Royal Eye Hospital,

Manchester MI3WL, UK

Tel +44 I6। 2765502

Fax +44 7547339932

Email khaled.alzahrani@postgrad. manchester.ac.uk
Purpose: To compare the corneal clarity measurement between penetrating keratoplasty (PK) and deep anterior lamellar keratoplasty (DALK) in patients with keratoconus, using densitometry software for the Oculus Pentacam.

Methods: A retrospective comparative study was carried out at Manchester Royal Eye Hospital. Data were collected 12-18 months after corneal transplantation for keratoconus, including postoperative corneal densitometry, best corrected visual acuity (BCVA), central corneal thickness (CCT), and other relevant clinical details.

Results: Analysis of 37 keratoconus eyes from 36 patients found there was a significantly higher corneal densitometry measurement after DALK than PK. This was predominantly in the posterior layer of the concentric zone $0-2 \mathrm{~mm}$ of the cornea $(P=0.0004)$. A significant correlation was found between postoperative BCVA and corneal densitometry in DALK groups at full thickness $(P=0.03)$. This correlation was seen in the central $0-2 \mathrm{~mm}(P=0.03)$ and posterior 0-2 mm ( $P=0.04)$ zones. In addition, within the DALK group, a correlation was found between central corneal thickness and densitometry at full thickness $2-6 \mathrm{~mm}(P=0.007)$, central 0-2 $(P=0.04)$, central 2-6 mm $(P=0.01)$, and at posterior $2-6 \mathrm{~mm}(P=0.01)$ zones.

Conclusion: This study showed that corneal densitometry measurement differs depending on the type of corneal transplantation used to treat keratoconus patients. Densitometry may have an important role to play in the final BCVA achieved by patients undergoing corneal transplantation for keratoconus. Analysis of Oculus Pentacam images provides an objective evaluation to monitor the cornea status after the surgery.

Keywords: keratocytes, corneal transplantation, corneal wound healing, keratoconus, transparency

\section{Introduction}

Keratoconus $(\mathrm{KCN})$ is a non-inflammatory ectatic dystrophy characterized by successive thinning, steepening, and apical conical projection of the cornea. Irregular astigmatism and myopic changes result in progressive visual impairment, which arises due to shifts in the shape of the cornea. ${ }^{1}$ In $\mathrm{KCN}$, vision is improved with spectacle correction and/or soft contact lenses until irregular astigmatism demands the use of rigid gas permeable ( $\mathrm{RGB}$ ) contact lenses. ${ }^{2,3}$ In severe cases, a corneal transplant may be necessary for visual improvement. ${ }^{4}$

When a corneal transplant is deemed necessary, a full thickness penetrating keratoplasty $(\mathrm{PK})^{5}$ has historically been the treatment of choice. However, advances in surgical techniques over the last decade have led to less invasive procedures such as deep anterior lamellar keratoplasty (DALK) becoming more popular. ${ }^{6}$ 
PK involves the complete replacement of the affected (8-9 mm) cornea with healthy donor corneal tissue. However, it is now the trend to perform lamellar transplants, aimed at replacing only abnormal corneal tissue. ${ }^{7}$ DALK is now used to treat $\mathrm{KCN}$ and other diseases that may cause anterior scarring or ectasia. This procedure involves the replacement of only the affected corneal stroma and overlying epithelium, thereby preserving the patient's endothelial layer and Descemet's membrane. This established technique confers a number of advantages. Throughout this surgical procedure, the eye remains "closed", reducing the potential risk of intraocular infection (endophthalmitis) and choroidal hemorrhage. As the patient's own endothelial layer is preserved, the risk of rejection is significantly reduced. ${ }^{8}$ Structural integrity is preserved, thereby reducing the risk of traumatic graft dehiscence. ${ }^{9}$ One concern of this technique, however, has been the loss of best corrected visual acuity (BCVA), thought to be due to the interface between the donor and recipient tissue. ${ }^{10}$

The healthy cornea does not absorb discernible light, and the dispersal of light is minimal. Therefore, densitometry can provide a measurement of the level of the transparency of the cornea. Densitometry of the whole cornea can be measured in a single scan using the Pentacam. The standardization of the density begins from 0 to 100 . As a result, 0 implies that the cornea demonstrates no blurring, while 100 signifies that the cornea is totally obscure. ${ }^{11}$ The Pentacam (Oculus Inc., Wetzlar, Germany) facilitates assessment of the whole anterior section from the anterior corneal surface, through to the surface of the posterior lens by use of a rotary Scheimpflug camera. ${ }^{12}$

Despite the large number of transplants performed for keratoconus, no corneal densitometry measurements have been reported. Historically, post-surgery analyses for patients recovering from corneal grafts are conducted by use of qualitative analysis of slit-lamp bio microscopy. ${ }^{13-15}$ This is possibly inadequate, because it appears to differ from visit to visit and from clinician to clinician.

In this study we have used densitometry to assess and compare the outcome of both PK and DALK grafts in keratoconus patients.

\section{Methods}

\section{Participants}

This was a retrospective, comparative, and non-randomized cross-sectional study and was approved by Central Manchester University Hospitals NHS Foundation Trust, Manchester, UK and NREC local ethics committee. The research followed the tenets of the Declaration of Helsinki. Written informed consent was obtained from the subjects after explanation of the nature of the study. Patients with keratoconus attending the Manchester Royal Eye Hospital (MREH) cornea clinic were selected if they had undergone corneal transplantation, either DALK or PK. Inclusion criteria for the study were patients 18 years or above who had a postoperative follow-up between 12 and 18 months where Pentacam images had been taken.

Clinical notes were examined where relevant information, including patient age, gender, corneal disease, date of surgery, and type of surgery, were recorded for descriptive data analysis. Postoperative parameters including BCVA in $\log$ MAR, and clinical details were also extracted from the notes for data analysis.

\section{Surgical technique}

The surgical procedures (DALK and PK) were performed by one of three surgeons, who used the same surgical technique. ${ }^{7} \mathrm{PK}$ was performed with a standard technique using a Hessburg-Barron trephine (JedMed Instrument Co., St Louis, MO). ${ }^{16}$ All DALK procedures were performed using Anwar's big-bubble technique, ${ }^{17-19}$ with the aim to obtain a type 1 big-bubble. ${ }^{9}$

In all cases, the graft diameter was between 8.00 and $8.25 \mathrm{~mm}$. Corneal tissue was issued by NHS Blood and Transplant (UK) services. All tissue met or exceeded the minimum standard for transplantation to include a minimum cell count of 2,200 cells $/ \mathrm{mm}^{2}$ and a central clear cornea of $9.00 \mathrm{~mm}$. All recipients received tissue within a 30 years age difference. Wherever possible, all sutures had been removed before the time of imaging and BCVA measurements.

\section{Pentacam imaging}

Pentacam images are routinely used clinically to assess patients undergoing transplant surgery. A new update in the computer software now allows the corneal clarity to be measured from the same image across different corneal zones and layers. Pentcam gives numeric value of the clarity at anterior, central, posterior, and total depth layers. In addition, similar numeric values are given by Pentacam at $0-2$, 2-6, 6-10, and 10-12 $\mathrm{mm}$ of the concentric corneal zone, and for the total corneal dimeter. ${ }^{11}$ The protocol takes 5 min and is non-invasive. Patients were imaged prior to any other eye examination or drop administration. A single image of the cornea was taken at each visit. All images were taken by a trained member of staff in a darkened room to minimize the effect of ambient lighting on the corneal measurements. 
All images selected met the quality requirement, as determined by Pentacam analysis.

Postoperative data of corneal densitometry for all layers at zones $0-2 \mathrm{~mm}$ and $2-6 \mathrm{~mm}$, in addition to central corneal thickness (CCT) were retrieved from the Oculus Pentacam database. The measurements from the Pentacam images were compared with BCVA and CCT to determine if these quick and easy measurements could provide additional information on the surgical outcome of corneal transplants using different techniques.

\section{Statistical analysis}

Data analyses were performed using IBM SPSS Statistics for Mac, Version 23.0 (IBM Corp, Armonk, NY), and Graph pad prism7 for Windows. Descriptive statistics were presented as the mean \pm SD. Normality of data was examined using the Shapiro-Wilk test, which is more appropriate for small sample sizes ( $<50$ samples). Student's $t$-test for two independent samples was used when parametric analysis was possible. Pearson correlation (r) was used when looking at the relationship between surgical outcomes of the study. A $P$-value of $<0.05$ was considered to be statistically significant.

\section{Results}

A total of 37 eyes from 36 patients were studied in the keratoconus group. The sample characteristics are comparable between both groups. However, there were more males than females in this study (14:7 PK and 11:5 DALK). Both the PK and DALK groups showed good similarity in their demographic characteristics and demonstrated no statistical difference in the age of patients $(P=0.43)$ (Table 1). The mean period of time between surgery and BCVA measurement in this study was comparable, and showed no statistical significant between both groups $(P=0.80)$. In the PK group, $66 \%$ of eyes $(\mathrm{n}=14)$ achieved postoperative BCVA of 0.3 LogMAR (6/12) or better, while in the DALK group, $81 \%$ of

Table I Mean and SD of age, time of the densitometry, and BCVA in both PK and DALK

\begin{tabular}{llll}
\hline & PK, M (SD) & DALK, M (SD) & P-value \\
\hline Age & $30.14(9.67)$ & $32.56(8.73)$ & 0.43 \\
$\begin{array}{l}\text { Time of imaging } \\
\text { postsurgery (months) }\end{array}$ & $14.90(3.59)$ & $14.62(4.80)$ & 0.84 \\
$\begin{array}{l}\text { Time of taking BCVA } \\
\text { postsurgery (months) }\end{array}$ & $13.95(2.74)$ & $14.87(4.03)$ & $0.4 \mathrm{I}$ \\
BCVA & $0.33(0.21)$ & $0.25(0.22)$ & 0.28 \\
\hline
\end{tabular}

Abbreviations: BCVA, best corrected visual acuity; PK, penetrating keratoplasty; DALK, deep anterior lamellar keratoplasty; M, mean.
Table 2 Summary of the postoperative densitometry in the surrounding $0-2$ and 2-6 $\mathrm{mm}$ annulus zone of the cornea

\begin{tabular}{llll}
\hline $\begin{array}{l}\text { Corneal zones } \\
\text { and layers }\end{array}$ & PK, M(SD) & DALK, M (SD) & P-value \\
\hline 0-2 mm & & & \\
$\quad$ Anterior & $23.57(3.69)$ & $24.62(3.10)$ & 0.36 \\
Central & $19.40(2.02)$ & $20.62(1.68)$ & 0.07 \\
Posterior & $14.60(1.97)$ & $17.40(2.40)$ & $0.0004^{* *}$ \\
Full depth & $19.20(2.20)$ & $20.80(1.90)$ & $0.02^{*}$ \\
2-6 mm & & & \\
Anterior & $24.83(4.60)$ & $25.09(3.30)$ & 0.8 \\
Central & $20.19(3.60)$ & $19.88(2.07)$ & 0.3 \\
Posterior & $14.89(2.80)$ & $16.08(3.09)$ & 0.2 \\
Full depth & $19.97(3.56)$ & $20.36(2.47)$ & 0.7 \\
\hline
\end{tabular}

Note: **Signficant at $p<0.01$ and *signfcant at $p<0.05$.

Abbreviations: PK, penetrating keratoplasty; DALK, deep anterior lamellar keratoplasty.

eyes $(n=13)$ achieved postoperative BCVA of $0.3 \operatorname{LogMAR}$ $(6 / 12)$ or better.

There was no statistical significance between the mean period of time between surgery and densitometry measurements between the two groups. Table 1 summarizes the demographic data. Densitometry measurements were taken for both the central 0-2 $\mathrm{mm}$ and the surrounding 2-6 mm concentric zone; results are summarized in Table 2. The measurements showed that there is a significant statistical difference between the two groups when the full depth cornea was examined at $0-2 \mathrm{~mm}$ concentric zone $(P=0.02)$. However, further statistical analysis showed a higher corneal densitometry measurement in the posterior layer after DALK, which was statistically significant for the $0-2 \mathrm{~mm}$ of the cornea zone $(P=0.0004)$. There was no statistical difference in postoperative central corneal thickness between the two groups (Table 3).

There was a correlation, but it did not reach significance, between postoperative BCVA and the densitometry measurement after the surgery in the keratoconus group for PK, except with the posterior layer at zone $2-6 \mathrm{~mm}$ of the cornea, which was statistically significant at $P<0.05$ (Figure 1).

In the DALK group, a correlation was shown between BCVA and the densitometry measurement after the surgery. These correlations were found at central zone at $0-2 \mathrm{~mm}$ corneal concentric zone. Correlation with BCVA was found also in the posterior layer of the corneal zone at $0-2 \mathrm{~mm}$

Table 3 Corneal thickness postsurgery in both groups

\begin{tabular}{llll}
\hline & PK, M (SD) & DALK, M (SD) & P-value \\
\hline CCT & $54 I(32.5)$ & $556(4 I .9)$ & 0.20 \\
Thinnest area & $513(50.5)$ & $539(34.7)$ & 0.07 \\
\hline
\end{tabular}

Abbreviations: PK, penetrating keratoplasty; DALK, deep anterior lamellar keratoplasty; M, mean; CCT, central corneal thickness. 

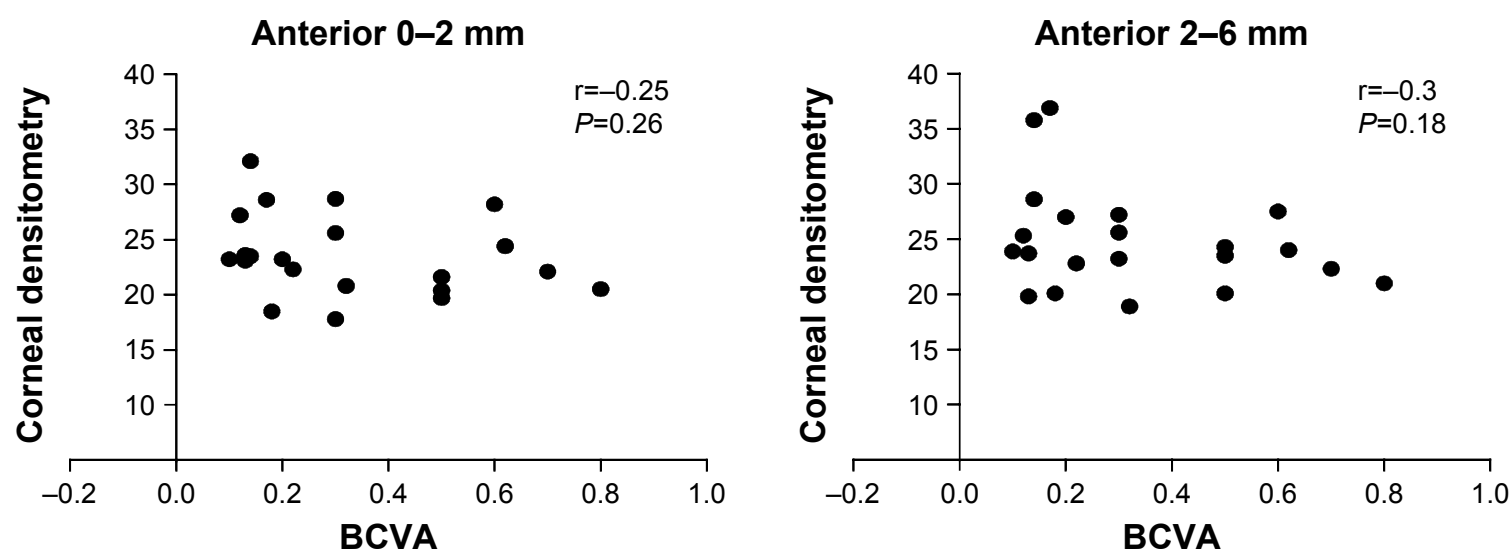

Central 0-2 mm

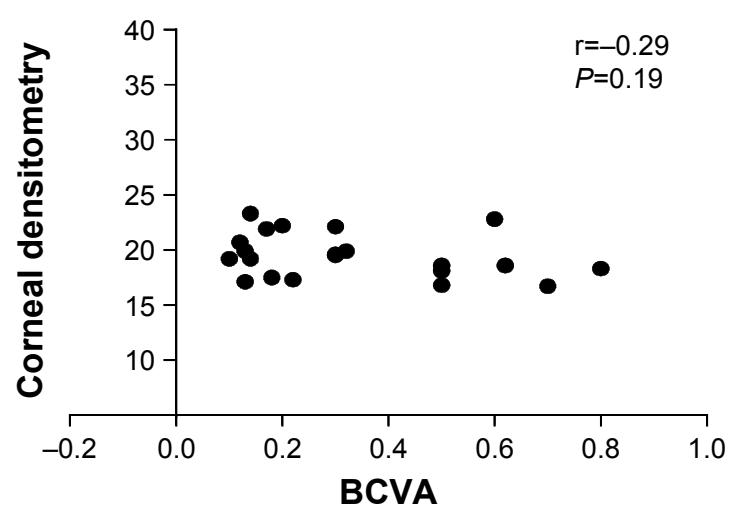

Central 2-6 mm

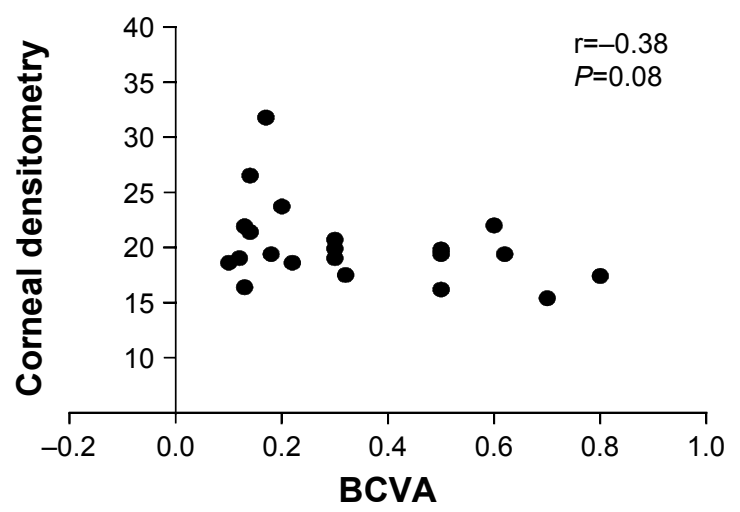

Posterior 0-2 mm

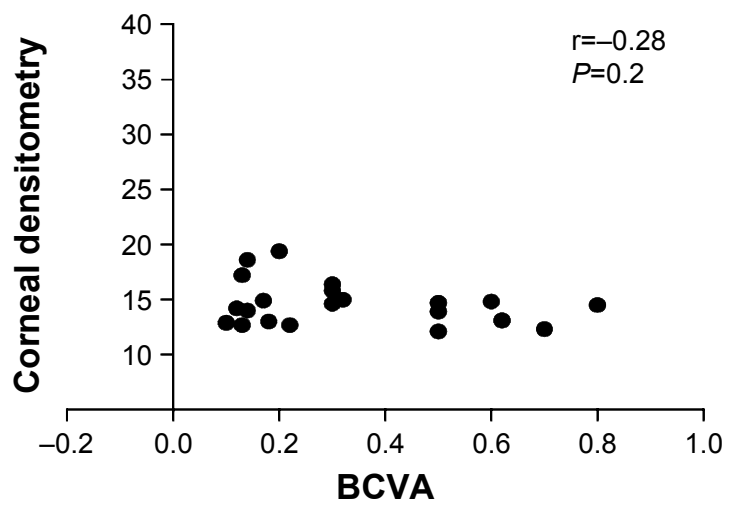

Posterior 2-6 mm

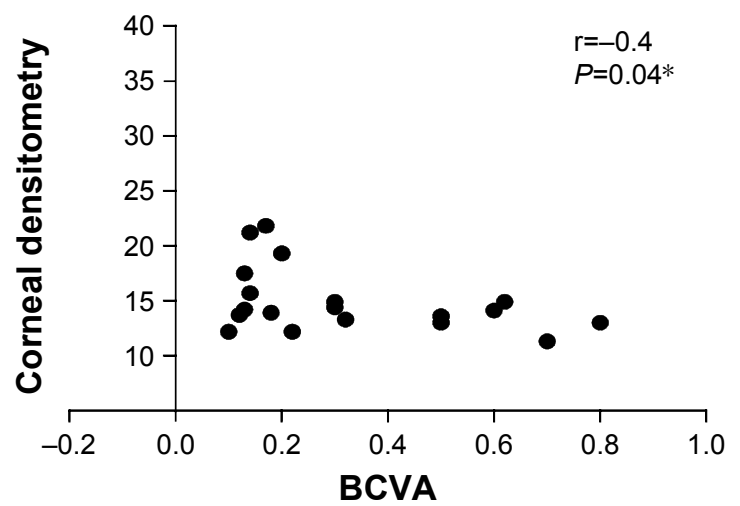

Full depth 0-2 mm

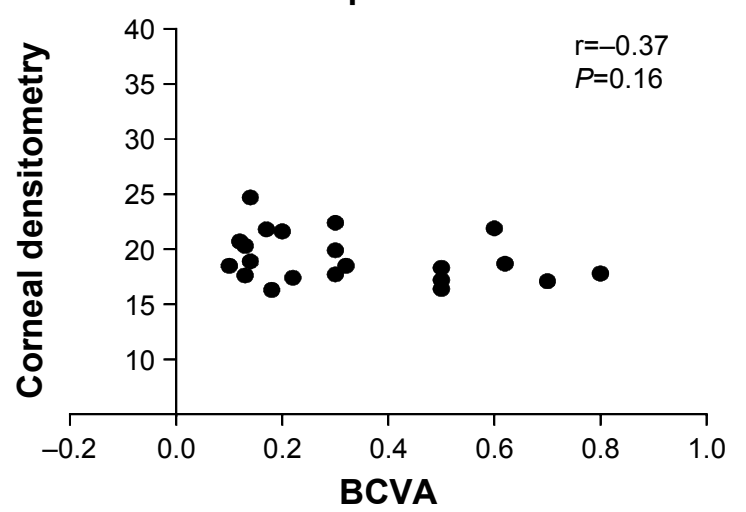

Full depth 2-6 mm

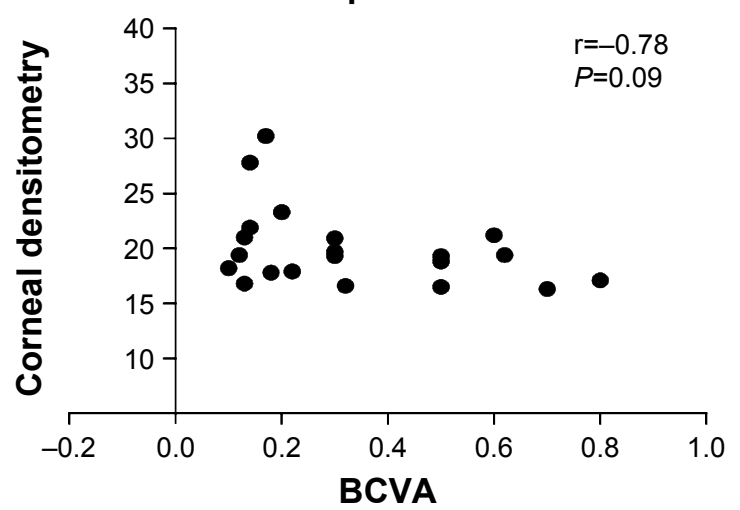

Figure I Correlation between BCVA and corneal densitometry in different corneal zones and layers in the PK group ( $r=$ correlations coefficient). Note: *Significant at $P<0.05$.

Abbreviations: BCVA, best corrected visual acuity; PK, penetrating keratoplasty. 
and at the full depth of corneal zone at $0-2 \mathrm{~mm}, P<0.05$ (Figure 2).

Central corneal thickness was found to be correlated with corneal densitometry in the DALK group only. These correlations were found to take place at full depth 2-6 mm, posterior 2-6 $\mathrm{mm}$, and at both central $0-2 \mathrm{~mm}$ and $2-6 \mathrm{~mm}$, $P<0.05$ (Figure 3).

\section{Discussion}

DALK is becoming the procedure of choice when corneal transplantation is needed to treat advanced keratoconus. It has several advantages compared to $\mathrm{PK}$ as it reduces the number of risk factors related to intraocular surgery, resulting in fewer allograft rejections and other long-term problems. ${ }^{20}$

This study has shown that, between 12 and 18 months after surgery, the mean corneal densitometry for patients with $\mathrm{KCN}$, having had either PK or DALK, was still higher compared to a normal control value within a matched-age group, as illustrated by Dhubhghaill et $\mathrm{al}^{21}$ and Alzahrani et al. ${ }^{22}$ At all corneal regions, apart from the central area at 2-6 mm annulus, the average corneal densitometry was greater in DALK than PK. This suggests that a greater scattering of light was provided by DALK as opposed to PK. Variations in corneal densitometry quantification at the posterior layer were statistically significant $(P<0.05)$ in the $0-2 \mathrm{~mm}$ corneal zone. This result in the DALK group suggests the host/ donor interface reduces clarity, and could have an effect on vision. ${ }^{23}$

The corneal densitometry was quantified using the manufactures pre-set for the posterior $60 \mu \mathrm{m}$ of the cornea. In DALK, the quantification of densitometry may be even higher if the quantification marker has been customized to concentrate on the host/donor interface of the region. The same pre-set was applied for all layers, the host/donor interface morphology, which results in considerably greater quantification of densitometry in the posterior layer following DALK, which is best described by research employing confocal microscopy. When employing a confocal microscope after DALK, researchers ${ }^{24}$ discovered a keratocyte configuration that was uneven and minimized as compared to PK in keratoconus. Several contributory elements were considered by Feizi et $\mathrm{al}^{24}$ to clarify their results, including mechanical injury of the host and donor sides during surgery, and transient lack of an endothelium pump, resulting in an influx of fluid at the interface (Marchini et al). ${ }^{25}$

A subsequent wound healing response may also cause undesirable complications like corneal haze, which may reduce corneal clarity. Remodeling of the extracellular matrix and repopulation of keratocytes following the surgical induced injury of DALK can influence the corneal transparency resulting from reorganization of the corneal fibrils. Netto et al, ${ }^{26}$ showed that significant apoptosis has been detected within $4 \mathrm{~h}$ after corneal injury. Following keratocyteapoptosis, the cells undergo secondary necrosis and later activate other keratocytes at deeper layers of the stroma. In addition, there is an activation of inflammatory cells to invade the stromal layer and engulf the resulting dead cells. ${ }^{27}$ Keratocytes that die in the anterior stroma are replenished in just 2-4 days by proliferation and migration of neighboring keratocytes. ${ }^{28}$ The proliferation and migration of residually activated keratocytes begins 12-24 h after epithelial injury. These activated cells may start synthesizing matrix metalloproteinases for tissue remodeling. The replenishing cells in the anterior keratocytes are the activated myofibroblast cells between 1 and 2 weeks postinjury, which produce collagen, hyaluronic acid, growth factors modulating epithelial healing, and more. ${ }^{26}$ The role of myofibroblast cells is very important in remodeling the extracellular matrix and stroma.

The whole process of keratocytes apoptosis, secondary necrosis, activation, proliferation, migration, and transformation regulates corneal wound healing and, consequently, causes haze formation. ${ }^{29}$ As discussed above, the raised densitometry quantification in DALK could be the result of mechanical injury from the surgical technique used within this study. It would be interesting to contrast the densitometry result in different DALK procedures to include those performed using Big-Bubble type 1, Big-Bubble type 2, and manual dissection.

It is debateable if reduced endothelial cell density (ECD) can also contribute to our results, as the endothelium pump is crucial for sustaining the transparency of the cornea. It was established $^{30}$ that, if there was no perforation of Descement's membrane (DM) in surgery, there was considerably less attrition of endothelial cells following DALK as opposed to PK. ${ }^{10,31,32}$ This raises the question that, as the host's own endothelium is maintained by DALK, is the reduction in the transparency of the cornea in DALK entirely due to the host/donor interface following this technique when ECD is higher as opposed to PK.

Our study demonstrated that the average postoperative BCVA result employing the LogMAR chart in DALK is better than that of PK, although this does not reach statistical significance. This was interesting but unexpected, given the raised corneal densitometry quantified in the DALK patients. There are uncertainties surrounding the quality of vision after DALK. There is conflicting published evidence on BCVA, with some studies demonstrating similarity between PK and DALK, ${ }^{33-35}$ whilst others have reported decreased vision in eyes after DALK. ${ }^{23,36,37}$ However, a numbers of studies have 

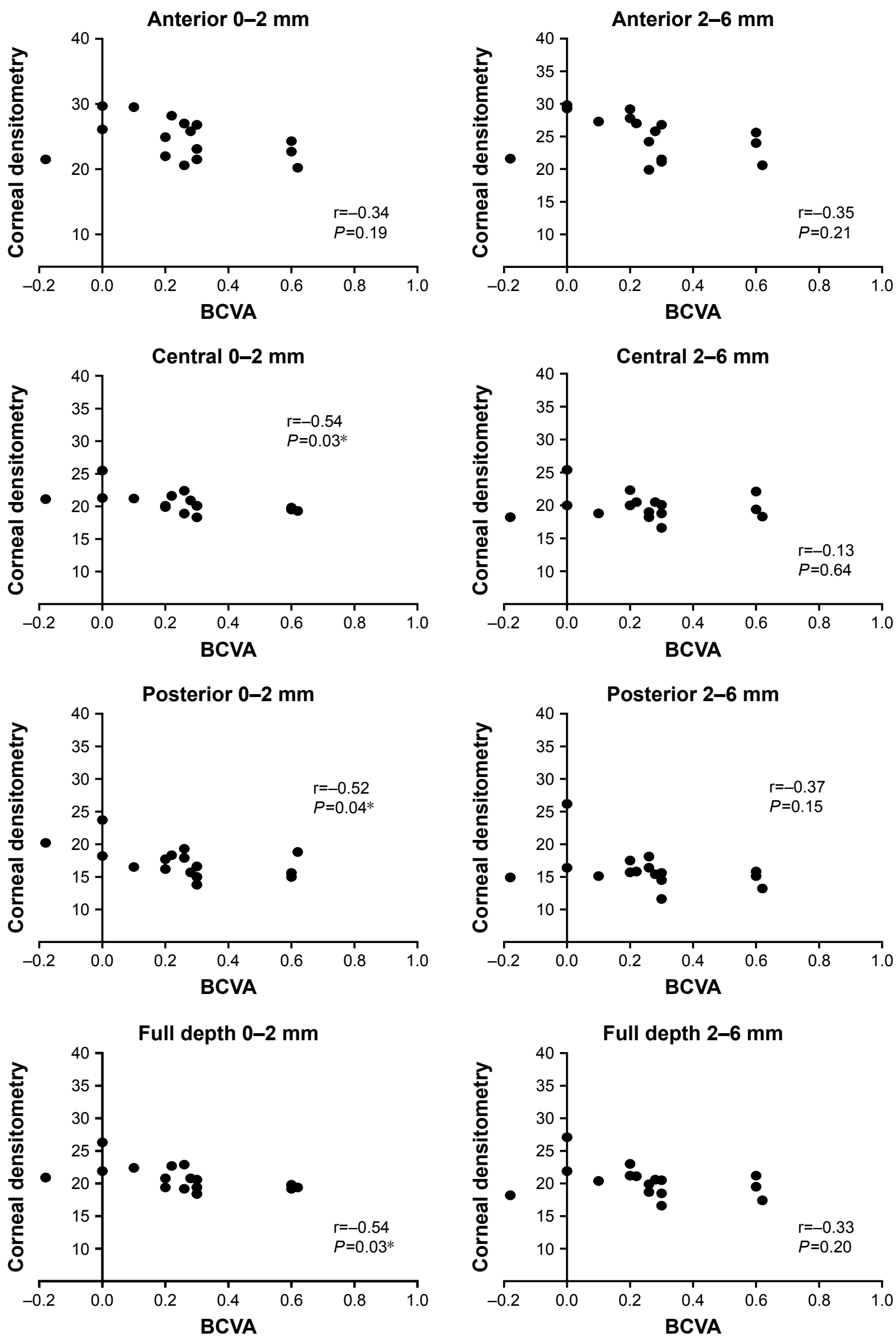

Figure 2 Correlation between BCVA and corneal densitometry in different corneal zones and layers for the DALK groups. ( $r=$ correlations coefficient). Note: *Significant at $P<0.05$.

Abbreviations: BCVA, best corrected visual acuity; DALK, deep anterior lamellar keratoplasty. 

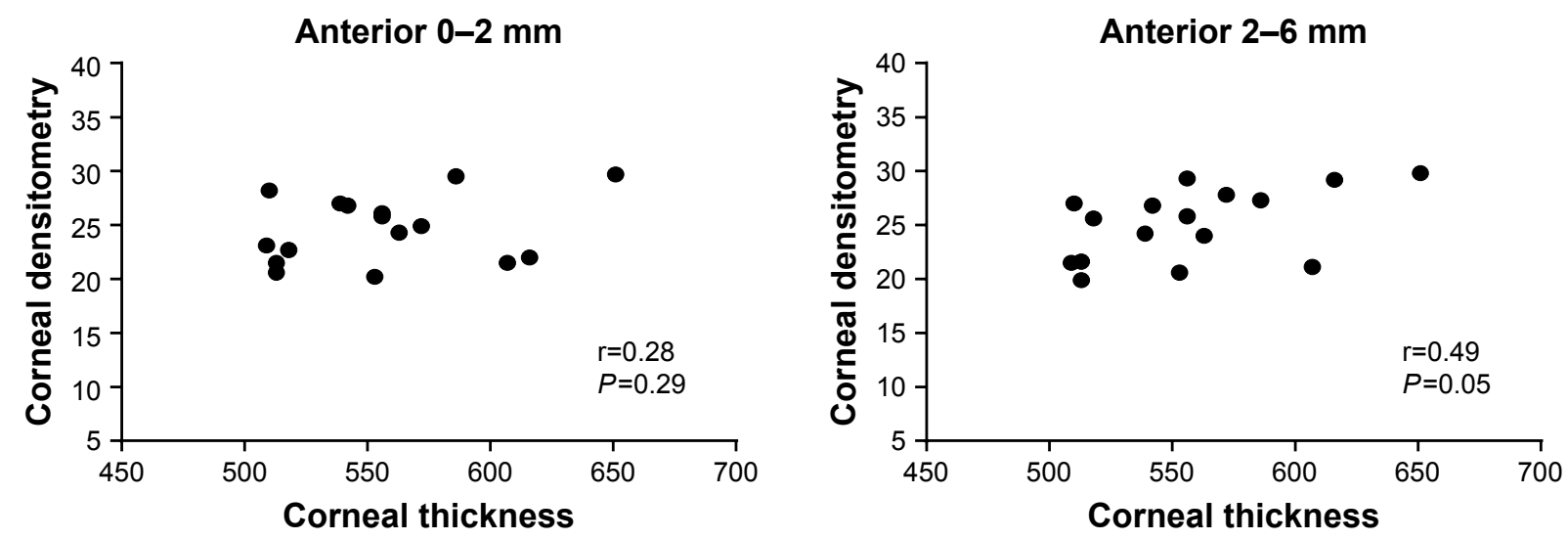

Central 0-2 mm

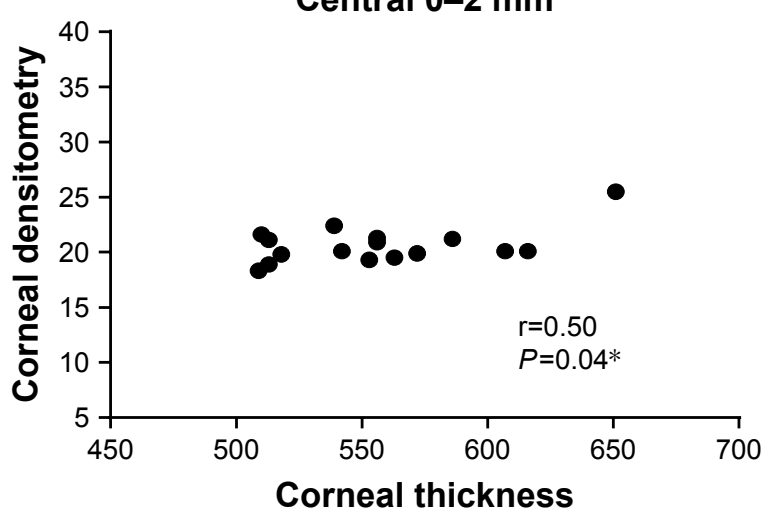

Central 2-6 mm
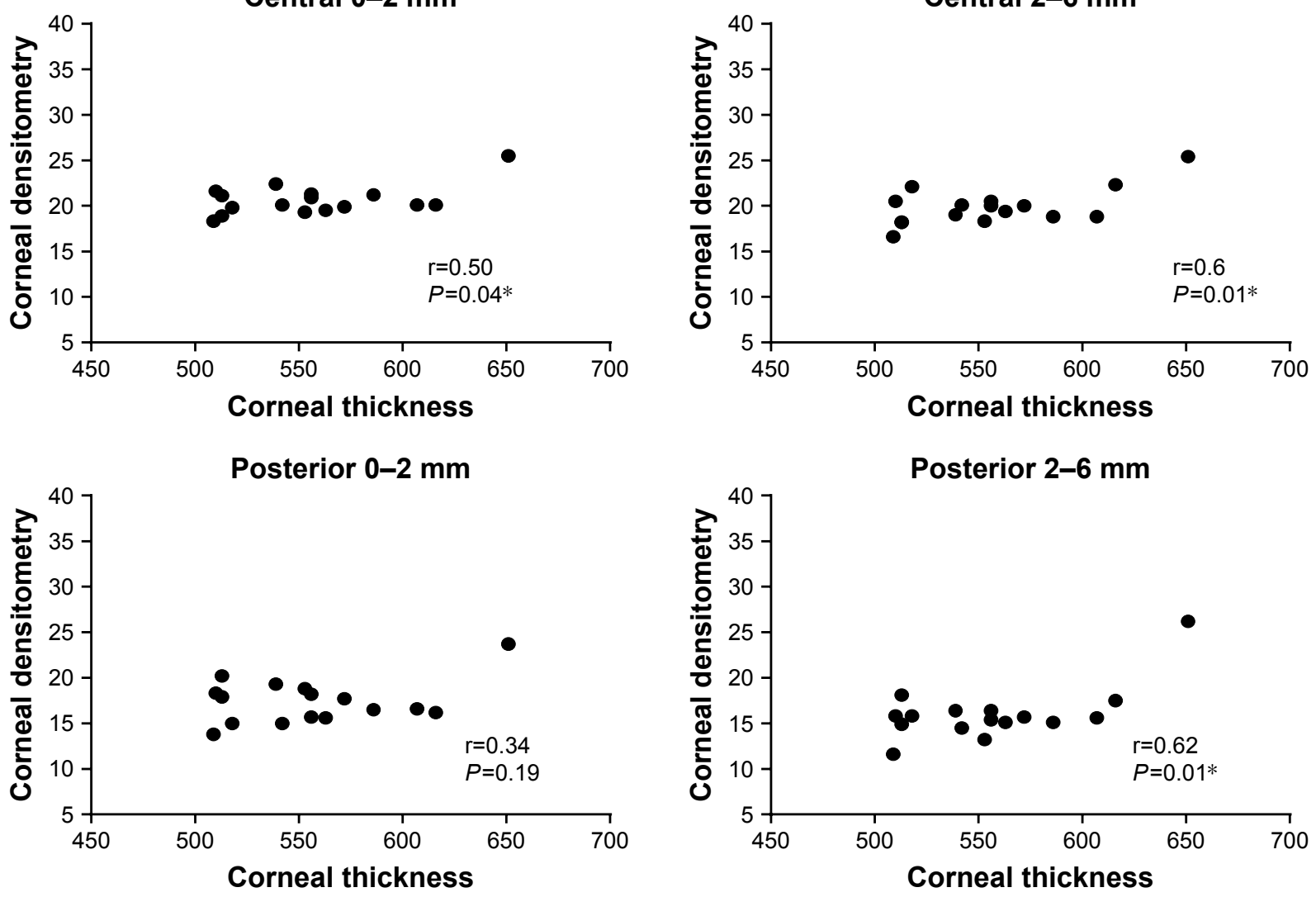

Full depth 0-2 mm

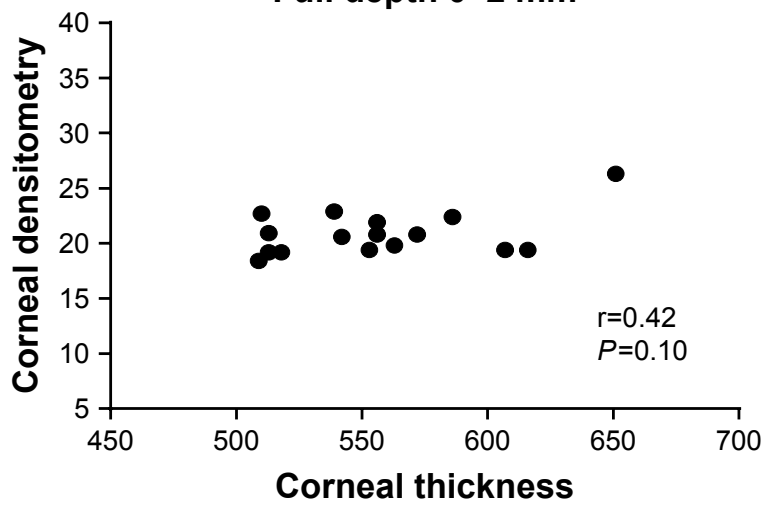

Full depth 2-6 mm

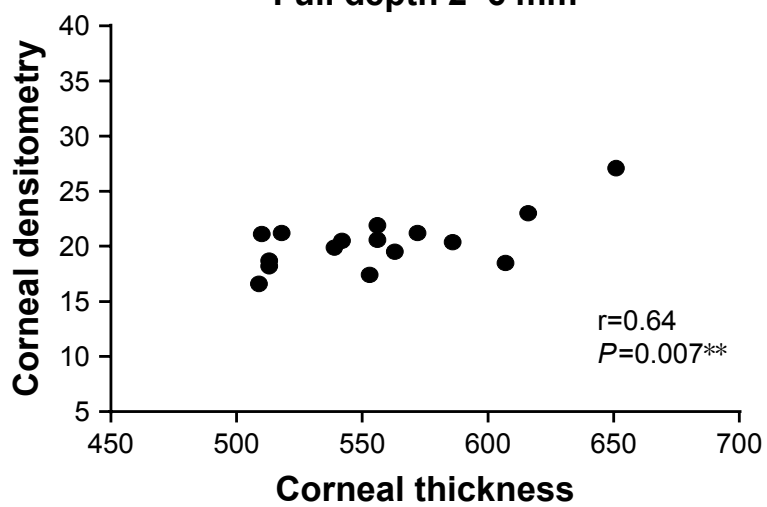

Figure 3 Correlation between central corneal thickness and corneal densitometry in different corneal zones and layers in the DALK group ( $r=$ correlations coefficient) Note: *Significant at $P<0.05$ and $* * P<0.01$.

Abbreviation: DALK, deep anterior lamellar keratoplasty. 
concluded that DALK provides better BCVA, ${ }^{36,38-40}$ in keeping with our own findings. Researchers have proposed that, after lamellar graft surgery, unevenness at the host/donor interface could reduce vision in some eyes. ${ }^{41}$ The almost complete exposure of DM by using the big-bubble technique most likely has a role in the improved postoperative BCVA in DALK, as opposed to PK. ${ }^{35}$

The limitation in this study was its retrospective nature and the relatively small sample size for each group that could impede statistical analysis, hence a larger sample size would increase the strength of any further analysis.

In conclusion, this study has found increased densitometry measurements in DALK compared to PK, primarily at the posterior layer within the $0-2 \mathrm{~mm}$ zone. This doesn't appear to have an effect on BCVA when compared with those patients undergoing $\mathrm{PK}$ for $\mathrm{KCN}$. We have discussed a number of factors which may have contributed to the raised densitometry result.

This is the first study to demonstrate raised densitometry in patients undergoing DALK and provides further information on this lamellar technique. In the future, other forms of corneal imaging to include spectral domain optical coherence tomography and confocal microscopy may help provide greater understanding on this important surgical zone. Corneal densitometry measurements provided by the Oculus Pentacam provide an objective evaluation to further monitor the treatment outcome of corneal transplants surgery in $\mathrm{KCN}$. It provides a non-invasive technique which is safe to use and useful in planning the management of surgery.

\section{Acknowledgments}

The authors thank the Manchester Royal Eye hospital (Corneal Clinic) for supporting patient's recruitments for this study. The study was supported by the Armed Forces Medical Services, Ministry of Defence, Riyadh, Saudi Arabia.

\section{Disclosure}

The authors report no conflicts of interest in this work.

\section{References}

1. Krachmer JH, Feder RS, Belin MW. Keratoconus and related noninflammatory corneal thinning disorders. Surv Ophthalmol. 1984;28(4): 293-322.

2. Smiddy WE, Hamburg TR, Kracher GP, Stark WJ. Keratoconus. Contact lens or keratoplasty? Ophthalmology. 1988;95(4):487-492.

3. Atebara N, Asbell P, Azar D. Contact lens, Chapter 5. Clinical Optics, Basic and Clinical Science Course. San Franscisco, CA: American Academy of Ophthalmology; 2009:167-200.

4. Kanellopoulos AJ, Krueger RR, Asimellis G. Cross-linking and corneal imaging advances. Biomed Res Int. 2015;2015:306439.
5. Lass JH, Lembach RG, Park SB, et al. Clinical management of keratoconus. A multicenter analysis. Ophthalmology. 1990;97(4):433-445.

6. Jhanji V, Sharma N, Vajpayee RB. Management of keratoconus: current scenario. Br J Ophthalmol. 2011;95(8):1044-1050.

7. Keenan TD, Carley F, Yeates D, et al. Trends in corneal graft surgery in the UK. Br J Ophthalmol. 2011;95(4):468-472.

8. Jonuscheit S, Doughty MJ. Corneal transplantation for keratoconus. Scand J Optom Vis Sci. 2013;6(1):1-8.

9. McKee HD, Barua A, Brahma AK, Jhanji V, Carley FM. Rupture pressure of the posterior lamella obtained during big-bubble deep anterior lamellar keratoplasty. Cornea. 2012;31(11):1285-1287.

10. Reinhart WJ, Musch DC, Jacobs DS, Lee WB, Kaufman SC, Shtein RM. Deep anterior lamellar keratoplasty as an alternative to penetrating keratoplasty. A report by the American Academy of Ophthalmology. Ophthalmology. 2011;118(1):209-218.

11. Cho YK, Chang HS, La TY, et al. Anterior segment parameters using Pentacam and prediction of corneal endothelial cell loss after cataract surgery. Korean J Ophthalmol. 2010;24(5):284-290.

12. Swartz T, Marten L, Wang M. Measuring the cornea: the latest developments in corneal topography. Curr Opin Ophthalmol. 2007;18(4): 325-333.

13. Rowsey JJ, Fowler WC, Terry MA, Scoper SV. Use of keratoscopy, slitlamp biomicroscopy, and retinoscopy in the management of astigmatism after penetrating keratoplasty. Refract Corneal Surg. 1991;7(1):33-41.

14. Price FW, Price MO. Descemet's stripping with endothelial keratoplasty in 200 eyes: early challenges and techniques to enhance donor adherence. J Cataract Refract Surg. 2006;32(3):411-418.

15. Moutsouris K, Dapena I, Ham L, Balachandran C, Oellerich S, Melles GR. Optical coherence tomography, Scheimpflug imaging, and slitlamp biomicroscopy in the early detection of graft detachment after Descemet membrane endothelial keratoplasty. Cornea. 2011;30(12): 1369-1375.

16. Lim L, Pesudovs K, Coster DJ. Penetrating keratoplasty for keratoconus: visual outcome and success. Ophthalmology. 2000;107(6): 1125-1131.

17. Anwar M, Teichmann KD. Big-bubble technique to bare Descemet's membrane in anterior lamellar keratoplasty. J Cataract Refract Surg. 2002;28(3):398-403.

18. Jhanji V, Beltz J, Sharma N, Graue E, Vajpayee RB. "Double bubble" deep anterior lamellar keratoplasty for management of corneal stromal pathologies. Int Ophthalmol. 2011;31(4):257-262.

19. Melles GR, Remeijer L, Geerards AJ, Beekhuis WH. A quick surgical technique for deep, anterior lamellar keratoplasty using visco-dissection. Cornea. 2000;19(4):427-432.

20. Olson EA, Tu EY, Basti S. Stromal rejection following deep anterior lamellar keratoplasty: implications for postoperative care. Cornea. 2012;31(9):969-973.

21. Dhubhghaill SN, Rozema JJ, Jongenelen S, Hidalgo IR, Zakaria N, Tassignon M-J. Normative values for corneal densitometry analysis by Scheimpflug optical assessment. Invest Ophthalmol Vis Sci. 2014; 55(1):162-168.

22. Alzahrani K, Carley F, Brahma A, Morley D, Hillarby MC. Corneal clarity measurements in healthy volunteers across different age groups: observational study. Medicine. 2017;96(46):e8563.

23. Funnell CL, Ball J, Noble BA. Comparative cohort study of the outcomes of deep lamellar keratoplasty and penetrating keratoplasty for keratoconus. Eye (Lond). 2006;20(5):527-532.

24. Feizi S, Javadi MA, Kanavi MR. Cellular changes of donor corneal tissue after deep anterior lamellar keratoplasty versus penetrating keratoplasty in eyes with keratoconus: a confocal study. Cornea. 2010;29(8): 866-870.

25. Marchini G, Mastropasqua L, Pedrotti E, Nubile M, Ciancaglini M, Sbabo A. Deep lamellar keratoplasty by intracorneal dissection: a prospective clinical and confocal microscopic study. Ophthalmology. 2006;113(8):1289-1300.

26. Netto MV,MohanRR, Ambrosio RJr, Hutcheon AE,ZieskeJD, Wilson SE. Wound healing in the cornea: a review of refractive surgery complications and new prospects for therapy. Cornea. 2005;24(5):509-522. 
27. Zieske JD, Guimaraes SR, Hutcheon AE. Kinetics of keratocyte proliferation in response to epithelial debridement. Exp Eye Res. 2001;72(1):33-39.

28. Alio JL, Javaloy J. Corneal inflammation following corneal photoablative refractive surgery with excimer laser. Surv Ophthalmol. 2013;58(1):11-25.

29. Abdelkader A, Elewah el SM, Kaufman HE. Confocal microscopy of corneal wound healing after deep lamellar keratoplasty in rabbits. Arch Ophthalmol. 2010;128(1):75-80.

30. Cheng YY, Visser N, Schouten JS, et al. Endothelial cell loss and visual outcome of deep anterior lamellar keratoplasty versus penetrating keratoplasty: a randomized multicenter clinical trial. Ophthalmology. 2011;118(2):302-309.

31. Kubaloglu A, Sari ES, Unal M, et al. Long-term results of deep anterior lamellar keratoplasty for the treatment of keratoconus. Am JOphthalmol. 2011;151(5):760-767.

32. Khattak A, Nakhli FR, Abdullatif Abouollo HM. Morphometric changes of corneal endothelial cells following intracameral air for micro perforation of the descemet membrane during big-bubble deep anterior lamellar keratoplasty. Saudi J Ophthalmol. 2016;30(2): 98-104.

33. Coombes AG, Kirwan JF, Rostron CK. Deep lamellar keratoplasty with lyophilised tissue in the management of keratoconus. Br JOphthalmol. 2001;85(7):788-791.
34. Shimazaki J, Shimmura S, Ishioka M, Tsubota K. Randomized clinical trial of deep lamellar keratoplasty vs penetrating keratoplasty. Am J Ophthalmol. 2002;134(2):159-165.

35. Sugita J, Kondo J. Deep lamellar keratoplasty with complete removal of pathological stroma for vision improvement. Br J Ophthalmol. 1997; 81(3):184-188.

36. Watson SL, Ramsay A, Dart JK, Bunce C, Craig E. Comparison of deep lamellar keratoplasty and penetrating keratoplasty in patients with keratoconus. Ophthalmology. 2004;111(9):1676-1682.

37. Panda A, Bageshwar LM, Ray M, Singh JP, Kumar A. Deep lamellar keratoplasty versus penetrating keratoplasty for corneal lesions. Cornea. 1999;18(2):172-175.

38. Tan DT, Mehta JS. Future directions in lamellar corneal transplantation. Cornea. 2007;26(9 Suppl 1):S21-S28.

39. Fontana L, Parente G, Tassinari G. Clinical outcomes after deep anterior lamellar keratoplasty using the big-bubble technique in patients with keratoconus. Am J Ophthalmol. 2007;143(1):117-124.

40. Borderie VM, Werthel AL, Touzeau O, Allouch C, Boutboul $\mathrm{S}$, Laroche L. Comparison of techniques used for removing the recipient stroma in anterior lamellar keratoplasty. Arch Ophthalmol. 2008;126(1):31-37.

41. Saini JS, Jain AK, Sukhija J, Saroha V. Indications and outcome of optical partial thickness lamellar keratoplasty. Cornea. 2003;22(2):111-113.
Clinical Ophthalmology

\section{Publish your work in this journal}

Clinical Ophthalmology is an international, peer-reviewed journal covering all subspecialties within ophthalmology. Key topics include: Optometry; Visual science; Pharmacology and drug therapy in eye diseases; Basic Sciences; Primary and Secondary eye care; Patien Safety and Quality of Care Improvements. This journal is indexed on

\section{Dovepress}

PubMed Central and CAS, and is the official journal of The Society of Clinical Ophthalmology (SCO). The manuscript management system is completely online and includes a very quick and fair peer-review system, which is all easy to use. Visit http://www.dovepress.com/ testimonials.php to read real quotes from published authors. 